\title{
Editorial
}

\section{Gene polymorphisms and diseases in Asians}

Human genome variability occurs by chance over several generations. When genetic variation occurs and disrupts the function of a particular gene, it is called mutation. When genetic variation occurs, but does not affect any particular gene function, it is called polymorphism. Despite the lack of functional effect, gene polymorphisms are known to be associated with certain disease conditions. The association can occur because the particular polymorphism is linked to a not-yet-known disease gene mutation.

It is well known that the incidence of many diseases varies between different ethnic groups. These are explained by genetic variation and susceptibility to disease process. Because variations in the genome occur randomly, certain types of mutation and polymorphism exist in particular ethnic groups. Therefore, when a particular genomic variation and disease association is identified, there is a need to verify usefulness in ethnic groups.

Two examples from this issue of the journal illustrate this topic. Acute lymphoblastic leukemia (ALL) is one of the most curable cancers of childhood. The cure is attributed to risk-adapted treatment for ALL. Mutation of critical gene loci result in clonal expansion of leukemic cells. The genetic analysis of leukemic cells has now been integrated in the risk classification and treatment. However, not been paid much attention has been paid to germline genetic background. The article by Mutiara et al., in this issue shows that response to chemotherapy is linked to polymorphism in the patient's germline multi-drug resistant (MDR) gene, in Indonesian children.

The prognostic significance of a gene can be meaningful in clinical decision making. If leukemia is likely resistant to chemotherapy, other therapeutic options can be offered earlier. Stem cell transplantation can be considered as soon as the patient is in remission, or in countries with limited resources, palliative care can be offered and save the children from suffering through a rigorous treatment that will not necessarily cure them.

Correspondence to: Issarang Nuchprayoon, Faculty of Medicine, Chulalongkorn University, Bangkok 10330, Thailand. E-mail: chulamed@md.chula.ac.th
The paper by Tanaviyutpakdee et al. in this issue explores interactions between the genetic polymorphisms of CYP2E1 a gene for a cytochrome P450 enzyme, and NQO1, a gene for an antioxidant enzyme, and dyslipidemia status in the general Thai population. These investigators show that in people with unfavorable lipid status (such as being hypercholesterolemic) and with a certain polymorphic allele, there are more measureable markers of oxidative stress. This evidence further links the adverse health effect of dyslipidemia with the oxidative stress level.

While genes cannot be modified, oxidative stress may be modulated to a certain extent by diet. Interventions to manage dyslipidemia include therapeutic drugs. If evidence for these conditions are confirmed, drug intervention can be effectively offered to people with susceptible genetic variants to reduce adverse effects and the cost of health care.

The gene-environment interaction is increasingly being investigated. With the advent of a higher throughput genome variation technology in recent years, it is easier to explore these complex interactions nowadays. Asian diets and lifestyle are unique to the region and so are genetic variations of its people.

\section{References}

1. Mutiara R, Agustinus B, Sitompul CB, Malik A, Gatot D, Suyatna FD. Multi drug resistance gene 1 polymorphism in pediatric patients with leukemia at a national referral hospital in Indonesia. Asian Biomed. 2015: 9;625-30.

2. Tanaviyutpakdee P, Yoovathaworn K, Sirivarasai J, Chanprasetyothin S, Panpunuan P, Petchpoung K, et al. Role of CYP2E1 and NQO1 polymorphism in oxidative stress derived cancer in Thais with and without dyslipidemia. Asian Biomed. 2015: 9;601-11. 